\title{
Vegetarianism as a protective factor for asymptomatic colonic diverticulosis in Asians: a retrospective cross-sectional and case-control study
}

\author{
Jihun Bong, Hyoun Woo Kang, Hyeki Cho, Ji Hyung Nam, Dong Kee Jang, Jae Hak Kim, Jun Kyu Lee, Yun Jeong Lim, \\ Moon-Soo Koh, Jin Ho Lee \\ Department of Internal Medicine, Dongguk University Ilsan Hospital, Dongguk University College of Medicine, Goyang, Korea
}

Background/Aims: Dietary fiber intake is considered a protective factor for diverticular disease such as diverticulitis. However, evidence for an inverse connection between dietary fiber consumption and asymptomatic colonic diverticulosis is lacking. Specifically, few studies have investigated this subject in Asians with different presentations of diverticulosis. Therefore, we assessed the protective effects of a vegetarian diet for asymptomatic colonic diverticulosis in Buddhist monks who are obligatory vegetarians for spiritual reasons compared with the general population. Methods: A retrospective, cross-sectional, case-control study was conducted in age- and sex-matched Buddhist monks and the general population who underwent colonoscopy for screening at a Korean health promotion center from August 2005 to June 2018. We compared the prevalence of asymptomatic diverticulosis between the 2 groups using a self-administered questionnaire. Results: In this study, a total of 1,316 individuals were included (Buddhist monks of 658 and general population of 658 ) with a mean age of $52.6 \pm 9.5$ years. The prevalence of asymptomatic diverticulosis in Buddhist monks was lower compared with the general population (6.7\% [44/658] vs. 10.8\% [71/658], $P=0.008$ ). Buddhist monks had a higher rate of high body mass index (BMI) and metabolic syndrome. By a multivariate regression analysis model, a nonvegetarian diet (odds ratio [OR], 1.82; 95\% confidence interval [CI], 1.21-2.72, $P=0.004$ ), old age (OR, 4.53; 95\% CI, 1.36-15.12; $P=0.014)$, male sex (OR, 1.91; 95\% CI, 1.28-2.85; $P=0.002)$, and a high BMI (OR, 1.50; 95\% CI, $1.01-2.23 ; P=0.047)$ were independent predictors of asymptomatic diverticulosis. Moreover, a nonvegetarian diet was associated with both right-sided and left-sided diverticulosis. Conclusions: A nonvegetarian diet may increase a risk of asymptomatic colonic diverticulosis in Asians. (Intest Res 2020;18:121-129)

Key Words: Diet, vegetarian; Buddhism; Asymptomatic; Diverticulosis

\section{INTRODUCTION}

Colonic diverticulosis is an acquired disease occurring by herniation of the mucosa through weak point in the colonic muscle wall. Approximately $60 \%$ of people older than 60 years in Westernized countries will develop asymptomatic or symptomatic diverticulosis. ${ }^{1,2}$ In most cases, the diverticulosis is as-

Received August 23, 2019. Revised September 25, 2019.

Accepted October 1, 2019.

Correspondence to Hyoun Woo Kang, Department of Internal Medicine,

Dongguk University Ilsan Hospital, Dongguk University College of Medicine,

27 Dongguk-ro, Ilsandong-gu, Goyang 10326, Korea. Tel: +82-31-961-7128,

Fax:+82-31-961-9309,E-mail: gangmali@naver.com ymptomatic, with only $10 \%$ to $25 \%$ of subjects with diverticulosis developing symptomatic diseases. ${ }^{3}$ Diverticular disease of the colon is defined as symptomatic and clinically significant diverticulosis which includes symptomatic uncomplicated diverticular disease, diverticulitis, diverticular bleeding, and segmental colitis associated with diverticular disease.

At present, diverticulosis is considered to be one of the most common GI disorders, and trends suggest an increasing incidence of associated complications and health care costs. ${ }^{4.7}$ It is an essential cause of hospital admissions and a tremendous contributor to healthcare prices in Western countries. ${ }^{5,8}$ Two features dominate the epidemiologic profile of diverticulosis: 
geography and age. Reports from countries such as Israel, Japan, Kenya, Singapore, and Uganda suggest a greater and growing prevalence of diverticulosis in these non-Western countries than previously realized..$^{9-12}$ The incidence of colonic asymptomatic diverticulosis in Korea is also growing. ${ }^{13}$ This may be associated with a Westernized lifestyle, population aging, and increasing number of screening colonoscopy. ${ }^{14}$

Several risk factors are known to be associated with colonic diverticular disease. Lifestyle factors, including high dietary intake of red meat, low fiber intake, lack of vigorous physical activity, obesity, and smoking, have been associated with diverticular disease. ${ }^{15,16}$ However, except old age and male sex, other predisposing factors for asymptomatic diverticulosis are largely unknown. The role of low fiber consumption in the formation of diverticulosis is also controversial. ${ }^{2,14,16-18}$ In particular, data about this association in Asians are unknown. The purpose of our study was to assess the effect of vegetarianism on asymptomatic colonic diverticulosis in Korean Buddhist monks who are obligatory vegetarians for spiritual reasons compared with the general population.

\section{METHODS}

\section{Study Population}

This was a case-control, cross-sectional study. We enrolled all individuals who got colonoscopy during a health check-up at the Medical Healthcare Center of Dongguk University Ilsan Hospital (Goyang, Korea) from August 2005 to June 2018. A total of 12,602 subjects, including 809 Buddhist priests, underwent colonoscopy for screening purposes during this period. Exclusion criteria were incomplete study due to cecal intubation failure; poor bowel preparation; repeated colonoscopic examination during the study period; medical history of colectomy, colorectal cancer, or diverticular disease; and severe abdominal symptoms such as abdominal pain or dyspepsia. Among the Buddhist monks, 151 subjects met 1 or more of the exclusion criteria; therefore, 658 Buddhist monks were included. To adjust for age and sex which are considered as important confounders in colonic diverticulosis, we formed a control group by randomly matching subjects from the general population according to age and sex (Fig. 1). The individuals who answered that they were vegetarian in the questionnaire were excluded from the general population group. Accordingly, 1,316 subjects were finally selected for this study. The Institutional Review Board of Dongguk University Hospital approved this study protocol (IRB No. 2019-02-017). The informed consent was waived.

\section{Clinical and Laboratory Evaluation}

All subjects were asked to complete questionnaires about abdominal symptoms (dyspepsia, abdominal pain, and hematochezia), smoking status, alcohol consumption, physical activity, and past medical history (Supplementary Material 1). This also included a question about the amount of weekly meat intake. All subjects' height, weight, waist circumference, and blood pressure were measured by skilled personnel with a

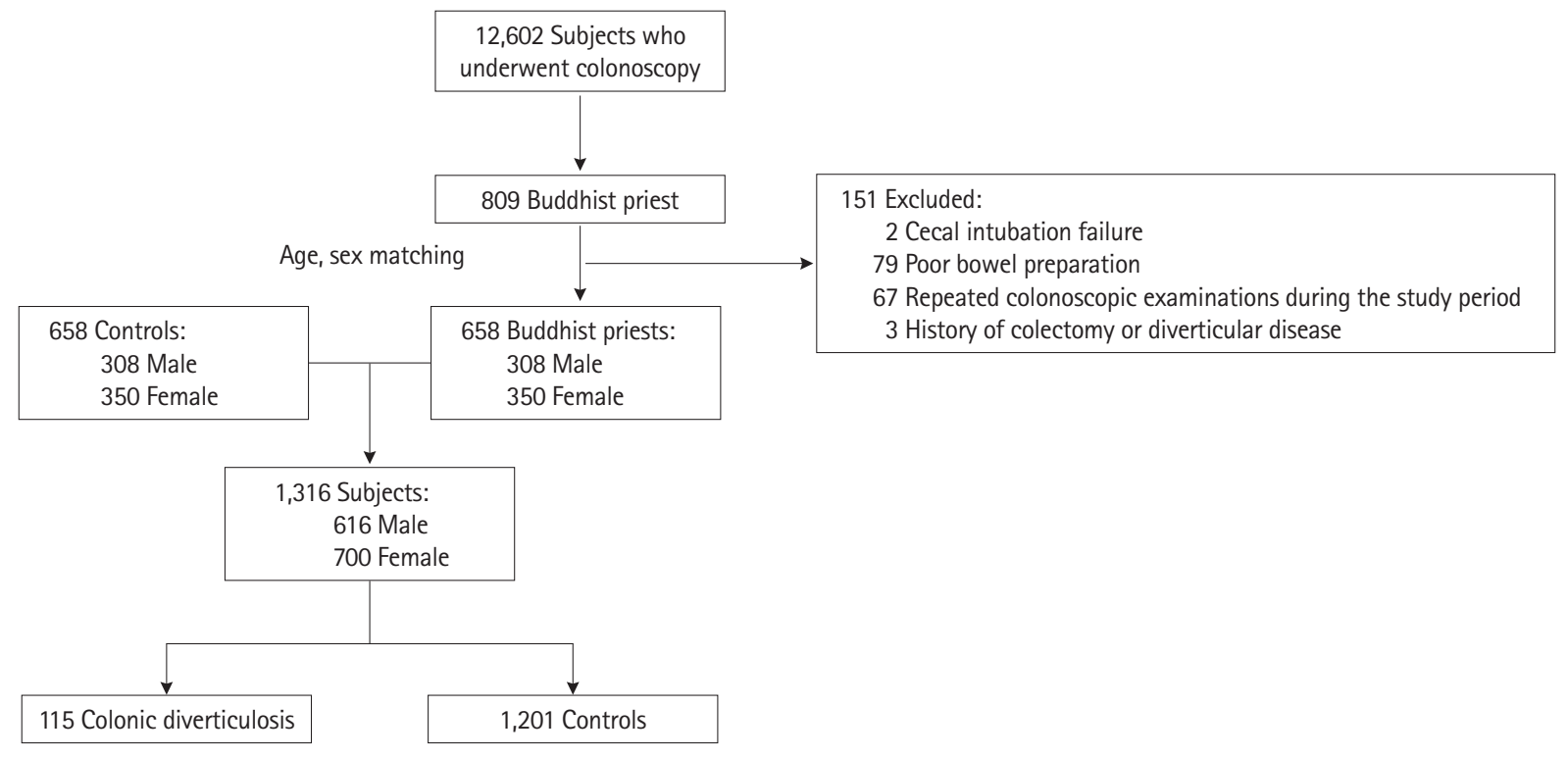

Fig. 1. Flow diagram of study population in this study. 
standardized protocol. Venous blood samples were gathered after overnight fasting. Blood complete cell counts, total cholesterol, triglycerides, HDL cholesterol, LDL cholesterol, fasting glucose, and hemoglobin Alc (HbAlc) were measured.

\section{Colonoscopy and Detection of Colonic Diverticulosis}

All colonoscopies were carried out by 8 experienced endoscopists with endoscopy specialty board certification. Standard colonoscopes (CF-H260AL or CF-H290L; Olympus Medical Systems, Tokyo, Japan) were used for colonoscopy. Most subjects underwent conscious sedation colonoscopy using intravenous midazolam and pethidine. If diverticulosis were observed, their locations were recorded. Three endoscopy professionals also reviewed all photographs of colonoscopies to find cases, in which diverticulosis had been forgotten to record by mistake. In addition, diverticulum is generally located between fold and another fold. So, if the endoscopist do not take much time during withdrawal, missing rate may increase. So, we analyzed colonoscopy withdrawal time as a quality indicator in both groups. Withdrawal time was calculated by picture archiving and communication system, in which the endoscopists captured the colonoscopic image with the present time simultaneously. We calculated the withdrawal time by subtracting the time between cecum to anus only in colonoscopies with negative results. We defined the location of diverticula as follows: the right side of the colon consist of the cecum, ascending colon, or transverse colon; the left side of the colon consist of the splenic flexure, descending colon, sigmoid colon, or rectum.

\section{Definitions}

Smoking meant smoking more than 1 cigarette regularly during the previous 1 year. Drinking meant drinking $>140 \mathrm{~g}$ of alcohol weekly. Hypertension meant $\geq 140 / 90 \mathrm{mmHg}$ or taking antihypertensive drugs. Individuals were diagnosed as metabolic syndrome in case that they met over 3 of the next 5 criteria: $^{19}$ (1) abdominal obesity (waist circumference $>90 \mathrm{~cm}$ in men and $>80 \mathrm{~cm}$ in women); (2) blood pressure $\geq 130 / 85$ mmHg or antihypertensive medication; (3) fasting plasma glucose $\geq 100 \mathrm{mg} / \mathrm{dL}$; (4) triglyceride levels $\geq 150 \mathrm{mg} / \mathrm{dL}$; and (5) HDL cholesterol $<40 \mathrm{mg} / \mathrm{dL}$ for men and $<50 \mathrm{mg} / \mathrm{dL}$ for women.

\section{Statistical Analyses}

Statistical analysis was carried out by SPSS version 23.0 for Windows (IBM Corp., Armonk, NY, USA). Student $t$-test or the
Mann-Whitney $U$-test for continuous factors and Pearson chisquare test (or Fisher exact test, when appropriate) for categorical factors were used to examine the association between colonic diverticulosis and the factors. ORs and 95\% CIs were calculated using conditional logistic regression. Variables with $P<0.05$ in the univariate analysis were added to the multivariate logistic regression analysis to detect independent risk factors for colonic diverticulosis. $P$-values $<0.05$ were considered statistically significant.

\section{RESULTS}

\section{Baseline Characteristics of the Study Population and Comparison between 2 Groups}

A total of 1,316 individuals were enrolled in this study (Bud-

Table 1. Baseline Characteristics between Buddhist Monk and General Population

\begin{tabular}{|c|c|c|c|}
\hline Characteristic & $\begin{array}{c}\text { Buddhist } \\
\text { monk } \\
(n=658)\end{array}$ & $\begin{array}{c}\text { General } \\
\text { population } \\
(n=658)\end{array}$ & $P$-value \\
\hline Age (yr) & $52.6 \pm 9.5$ & $52.6 \pm 9.5$ & 1.000 \\
\hline Male sex & $308(46.8)$ & $308(46.8)$ & 1.000 \\
\hline Current smoking & 0 & $103(15.7)$ & $<0.001$ \\
\hline Alcohol consumption & 0 & $113(17.2)$ & $<0.001$ \\
\hline Exercise ( $\geq 3$ times/wk) & 131 (19.9) & $161(24.5)$ & 0.054 \\
\hline Hypertension & $114(17.3)$ & $128(19.5)$ & 0.355 \\
\hline BMI $\left(\mathrm{kg} / \mathrm{m}^{2}\right)$ & $24.5 \pm 3.4$ & $23.7 \pm 3.1$ & $<0.001$ \\
\hline Metabolic syndrome & $156(23.7)$ & $117(17.8)$ & 0.008 \\
\hline $\mathrm{HbA1c}(\%)$ & $5.7 \pm 0.9$ & $5.6 \pm 0.8$ & 0.002 \\
\hline AST (IU/L) & $31.6 \pm 51.8$ & $30.8 \pm 17.4$ & 0.682 \\
\hline ALT (IU/L) & $31.5 \pm 79.2$ & $28.2 \pm 19.5$ & 0.286 \\
\hline Triglyceride (mg/dL) & $122.3 \pm 84.4$ & $120.1 \pm 83.1$ & 0.628 \\
\hline LDL cholesterol (mg/dL) & $131.8 \pm 34.6$ & $132.9 \pm 36.0$ & 0.576 \\
\hline HDL cholesterol (mg/dL) & $53.1 \pm 14.5$ & $58.7 \pm 15.5$ & $<0.001$ \\
\hline Total cholesterol (mg/dL) & $205.0 \pm 38.6$ & $198.2 \pm 39.1$ & $<0.001$ \\
\hline \multicolumn{4}{|l|}{ Diverticulosis } \\
\hline Total & $44(6.7)$ & 71 (10.8) & 0.008 \\
\hline Right-sided & $40(6.1)$ & $65(9.9)$ & 0.010 \\
\hline Left-sided & $6(0.9)$ & $18(2.7)$ & 0.006 \\
\hline Both-sided & $2(0.3)$ & $12(1.8)$ & 0.002 \\
\hline Withdrawal time & $\begin{array}{c}6 \min 24 \mathrm{sec} \pm \\
1 \mathrm{~min} 50 \mathrm{sec}\end{array}$ & $\begin{array}{c}6 \mathrm{~min} 17 \mathrm{sec} \pm \\
1 \mathrm{~min} 45 \mathrm{sec}\end{array}$ & 0.406 \\
\hline
\end{tabular}

Values are presented as mean \pm SD or number $(\%)$.

$\mathrm{HbA} 1 \mathrm{c}$, hemoglobin A1c.

Differences were considered significant when $P$-values were $<0.05$. 
dhists monks of 658 and general population of 658). The overall prevalence of colonic diverticulosis was $8.7 \%(115 / 1,316)$. The mean age of the 2 groups was $52.6 \pm 9.5$ years, and $46.8 \%$ had male sex. Between the 2 groups, there were no statistically significant differences regarding hypertension, exercise $\geq 3$ times/wk, AST, ALT, triglycerides, LDL, HDL levels and mean withdrawal time. Mean BMI $\left(24.5 \mathrm{~kg} / \mathrm{m}^{2}\right.$ vs. $\left.23.7 \mathrm{~kg} / \mathrm{m}^{2}, P<0.001\right)$, HbAlc ( $5.71 \%$ vs. $5.57 \%, P=0.002)$, and total cholesterol level $(205.0 \mathrm{mg} / \mathrm{dL}$ vs. $198.2 \mathrm{mg} / \mathrm{dL}, P<0.001)$ were higher and HDL level $(53.1 \mathrm{mg} / \mathrm{dL}$ vs. $58.7 \mathrm{mg} / \mathrm{dL}, P<0.001)$ was lower in the Buddhist monk group than in the general population group. Metabolic syndrome is more prevalent in the Buddhist monk group (23.7\% vs. $17.8 \%, P=0.008)$ and a lower prevalence of diverticulosis ( $6.7 \%$ vs. $10.8 \%, P=0.008$ ) than the control group. Both right-sided (6.1\% vs. 9.9\%, $P=0.010)$ and left-sided $(0.9 \%$ vs. $2.7 \%, P=0.006)$ diverticulosis were less prevalent in the Buddhist monk group (Table 1).

\section{Risk Factors for Colonic Diverticulosis}

It was investigated whether a vegetarian diet is associated with colonic diverticulosis using conditional regression analysis. By the univariate analysis, colonic diverticulosis was related with old age, male sex, BMI $\geq 25 \mathrm{~kg} / \mathrm{m}^{2}$, and a nonvegetarian diet. However, it was not associated with current smoking, alcohol consumption, or exercise (Table 2). Even in a conditional regression analysis model adjusted for age, male, BMI, and nonvegetarian diet, old age (age $\geq 60$ years vs. $\leq 39$ years: $O R, 4.53$; 95\% CI, 1.36-15.12; $P=0.014$ ), male sex (OR, 1.91; 95\% CI, 1.282.85; $P=0.002$ ), BMI $\geq 25 \mathrm{~kg} / \mathrm{m}^{2}$ (OR, 1.50; 95\% CI, 1.01-2.23; $P=0.047$ ), and nonvegetarian $\operatorname{diet}(\mathrm{OR}, 1.82 ; 95 \% \mathrm{CI}, 1.21-2.72$; $P=0.004$ ) were related with colonic diverticulosis (Table 3 ).

\section{Risk Factors for Right- or Left-Sided Colonic Diverticulosis}

We also examined whether a vegetarian diet is associated with

Table 2. Effect of Factors on Colonic Diverticulosis

\begin{tabular}{|c|c|c|c|c|}
\hline Factor & Control $(n=1,201)$ & Diverticulosis $(n=115)$ & OR (95\% Cl) & $P$-value \\
\hline Age (yr) & $52.29 \pm 9.49$ & $55.83 \pm 8.99$ & & $<0.001$ \\
\hline$\leq 39$ & $103(8.6)$ & $3(2.6)$ & 1 (reference) & \\
\hline $40-49$ & 388 (32.3) & $24(20.9)$ & $2.12(0.63-7.19)$ & 0.226 \\
\hline $50-59$ & $440(36.6)$ & $52(45.2)$ & $4.05(1.24-13.25)$ & 0.020 \\
\hline$\geq 60$ & $270(22.5)$ & 36 (31.3) & $4.58(1.38-15.19)$ & 0.013 \\
\hline Male sex & $544(45.3)$ & $72(62.6)$ & $2.02(1.36-3.00)$ & $<0.001$ \\
\hline Current smoking & $89(7.4)$ & $14(12.2)$ & $1.73(0.95-3.15)$ & 0.069 \\
\hline Alcohol consumption & $96(8.2)$ & $19(16.5)$ & $1.59(0.94-2.68)$ & 0.081 \\
\hline Exercise ( $\geq 3$ times/wk) & $271(22.6)$ & 24 (20.9) & $0.91(0.56-1.45)$ & 0.677 \\
\hline $\mathrm{BMI}\left(\mathrm{kg} / \mathrm{m}^{2}\right)$ & $24.00 \pm 3.23$ & $25.01 \pm 3.35$ & & 0.001 \\
\hline$<25$ & 761 (92.7) & $60(7.3)$ & 1 (reference) & \\
\hline$\geq 25$ & $440(88.9)$ & $55(11.1)$ & $1.59(1.08-2.33)$ & 0.019 \\
\hline Hypertension (present) & $228(19.0)$ & $28(24.3)$ & $1.37(0.88-2.15)$ & 0.165 \\
\hline Metabolic syndrome & $243(20.2)$ & $30(26.1)$ & $1.39(0.90-2.16)$ & 0.139 \\
\hline HbA1c (\%) & $5.63 \pm 0.84$ & $5.82 \pm 0.61$ & - & 0.090 \\
\hline AST (IU/L) & $31.17 \pm 40.06$ & $31.52 \pm 17.28$ & - & 0.927 \\
\hline ALT (IU/L) & $29.68 \pm 59.81$ & $31.37 \pm 27.12$ & - & 0.765 \\
\hline Triglyceride (mg/dL) & $120.40 \pm 83.70$ & $129.82 \pm 83.87$ & - & 0.249 \\
\hline LDL cholesterol (mg/dL) & $132.09 \pm 35.12$ & $134.53 \pm 37.01$ & - & 0.479 \\
\hline HDL cholesterol (mg/dL) & $56.00 \pm 15.25$ & $54.44 \pm 15.05$ & - & 0.296 \\
\hline Total cholesterol (mg/dL) & $201.60 \pm 38.67$ & $202.04 \pm 42.04$ & - & 0.906 \\
\hline Vegetarian diet & $614(51.1)$ & $44(38.3)$ & $1.69(1.14-2.50)$ & 0.008 \\
\hline
\end{tabular}

Values are presented as mean \pm SD or number $(\%)$.

HbA1c, hemoglobin A1c.

Differences were considered significant when $P$-values were $<0.05$. 
Table 3. Effect of Vegetarian Diet on Asymptomatic Colonic Diverticulosis by Univariate and Multivariate Analysis

\begin{tabular}{|c|c|c|c|c|c|c|}
\hline \multirow[b]{2}{*}{ Risk factor } & \multicolumn{2}{|c|}{ No. of person (\%) } & \multicolumn{2}{|c|}{ Univariate analysis } & \multicolumn{2}{|c|}{ Multivariate analysis $^{\mathrm{a}}$} \\
\hline & $\begin{array}{c}\text { Control } \\
(n=1,201)\end{array}$ & $\begin{array}{l}\text { Diverticulosis } \\
\quad(n=105)\end{array}$ & $\begin{array}{c}\text { OR } \\
(95 \% \mathrm{Cl})\end{array}$ & $P$-value & $\begin{array}{c}\text { OR } \\
(95 \% \mathrm{Cl})\end{array}$ & $P$-value \\
\hline Age (yr) & & & & 0.004 & & 0.006 \\
\hline$\leq 39$ & $103(8.6)$ & $3(2.6)$ & 1 (reference) & & 1 (reference) & \\
\hline $40-49$ & $388(32.3)$ & 24 (20.9) & $2.12(0.63-7.19)$ & 0.226 & $2.23(0.66-7.60)$ & 0.199 \\
\hline $50-59$ & $440(36.6)$ & $52(45.2)$ & $4.05(1.24-13.25)$ & 0.020 & $4.17(1.27-13.70)$ & 0.019 \\
\hline$\geq 60$ & $270(22.5)$ & 36 (31.3) & $4.58(1.38-15.19)$ & 0.013 & $4.53(1.36-15.12)$ & 0.014 \\
\hline Male sex & $544(45.3)$ & $72(62.6)$ & $2.02(1.36-3.00)$ & $<0.001$ & $1.91(1.28-2.85)$ & 0.002 \\
\hline $\mathrm{BMI}\left(\geq 25 \mathrm{~kg} / \mathrm{m}^{2}\right)$ & $440(36.6)$ & $55(52.4)$ & $1.59(1.08-2.33)$ & 0.019 & $1.50(1.01-2.23)$ & 0.047 \\
\hline Nonvegetarian diet & $614(51.1)$ & 44 (38.3) & $1.69(1.14-2.50)$ & 0.008 & $1.82(1.21-2.72)$ & 0.004 \\
\hline
\end{tabular}

${ }^{a}$ Adjusted for age, male, BMI, and vegetarian diet.

Table 4. Effect of Vegetarian Diet on Right-Sided Colonic Diverticulosis by Univariate and Multivariate Analysis

\begin{tabular}{|c|c|c|c|c|c|c|}
\hline \multirow[b]{2}{*}{ Risk factor } & \multicolumn{2}{|c|}{ No. of person (\%) } & \multicolumn{2}{|c|}{ Univariate analysis } & \multicolumn{2}{|c|}{ Multivariate analysis $^{a}$} \\
\hline & $\begin{array}{c}\text { Control } \\
(n=1,201)\end{array}$ & $\begin{array}{l}\text { Right-sided } \\
\text { diverticulosis } \\
(n=105)\end{array}$ & $\begin{array}{c}\text { OR } \\
(95 \% \mathrm{Cl})\end{array}$ & $P$-value & $\begin{array}{c}\text { OR } \\
(95 \% \mathrm{Cl})\end{array}$ & $P$-value \\
\hline Current smoking & $93(7.7)$ & $12(11.9)$ & $1.61(0.85-3.05)$ & 0.139 & & \\
\hline Alcohol consumption & $87(7.5)$ & $18(11.9)$ & $1.66(0.97-2.85)$ & 0.078 & & \\
\hline Hypertension & $84(7.9)$ & $21(8.8)$ & $1.13(0.69-1.87)$ & 0.692 & & \\
\hline Metabolic syndrome & $77(7.4)$ & $28(10.3)$ & $1.43(0.91-2.26)$ & 0.132 & & \\
\hline Exercise ( $\geq 3$ times/wk) & $270(22.5)$ & $20(19.0)$ & $0.81(0.49-1.35)$ & 0.464 & & \\
\hline Age (yr) & & & & 0.007 & & 0.012 \\
\hline$\leq 39$ & $103(8.6)$ & $3(2.6)$ & 1 (reference) & & 1 (reference) & \\
\hline $40-49$ & $388(32.3)$ & $24(20.9)$ & $1.95(0.57-6.63)$ & 0.287 & $2.04(0.60-6.99)$ & 0.256 \\
\hline $50-59$ & $440(36.6)$ & $52(45.2)$ & $3.67(1.12-12.02)$ & 0.032 & $3.76(1.14-12.97)$ & 0.030 \\
\hline$\geq 60$ & $270(22.5)$ & $36(31.3)$ & $4.20(1.26-13.98)$ & 0.020 & $4.14(1.24-13.87)$ & 0.021 \\
\hline Male sex & $544(45.3)$ & $64(61.0)$ & $1.89(1.25-2.84)$ & 0.002 & $1.78(1.17-2.69)$ & 0.007 \\
\hline $\mathrm{BMI}\left(\geq 25 \mathrm{~kg} / \mathrm{m}^{2}\right)$ & $440(36.6)$ & $50(41.6)$ & $1.59(1.08-2.33)$ & 0.028 & $1.50(1.01-2.27)$ & 0.047 \\
\hline Nonvegetarian diet & $587(48.9)$ & 65 (61.9) & $1.70(1.13-2.56)$ & 0.010 & $1.82(1.20-2.76)$ & 0.005 \\
\hline
\end{tabular}

${ }^{a}$ Adjusted for age, male, BMI, and vegetarian diet.

right-sided and left-sided diverticulosis. In univariate analysis, old age, male sex, higher BMI, and nonvegetarian diet were associated with right-sided colonic diverticulosis. In a multivariate analysis adjusted for age, male, BMI, and vegetarian diet, old age (age $\geq 60$ years vs. $\leq 39$ years: OR, $4.14 ; 95 \% \mathrm{CI}, 1.24-$ $13.87 ; P=0.021)$, male sex (OR, 1.78; 95\% CI, 1.17-2.69; $P=0.007)$, $\mathrm{BMI} \geq 25 \mathrm{~kg} / \mathrm{m}^{2}$ (OR, 1.50; 95\% CI, 1.01-2.27; $P=0.047$ ), and nonvegetarian $\operatorname{diet}(\mathrm{OR}, 1.82 ; 95 \% \mathrm{CI}, 1.20-2.76 ; P=0.005)$ were associated with an increased risk for right-sided colonic diverticulosis (Table 4).

Furthermore, old age, male sex, and nonvegetarian diet were associated with left-sided colonic diverticulosis in univariate analysis. Even in a conditional regression model, old age (OR, 3.50; 95\% CI, 1.51-8.11; $P=0.004$ ), male sex (OR, 5.55; 95\% CI, 1.86-16.5; $P=0.002)$, and nonvegetarian diet (OR, 3.90; 95\% CI, 1.43-10.67; $P=0.008)$ continued to be associated with increased risk for left-sided colonic diverticulosis (Table 5).

\section{DISCUSSION}

This study showed that a nonvegetarian diet was significantly associated with the risk of asymptomatic colonic diverticulo- 
Table 5. Effect of Vegetarian Diet on Left-Sided Colonic Diverticulosis by Univariate and Multivariate Analysis

\begin{tabular}{|c|c|c|c|c|c|c|}
\hline \multirow[b]{2}{*}{ Risk factor } & \multicolumn{2}{|c|}{ No. of person (\%) } & \multicolumn{2}{|c|}{ Univariate analysis } & \multicolumn{2}{|c|}{ Multivariate analysis $^{\mathrm{a}}$} \\
\hline & $\begin{array}{c}\text { Control } \\
(n=1,201)\end{array}$ & $\begin{array}{l}\text { Left-sided } \\
\text { diverticulosis } \\
(n=23)\end{array}$ & $\begin{array}{c}\text { OR } \\
(95 \% \mathrm{Cl})\end{array}$ & $P$-value & $\begin{array}{c}\text { OR } \\
(95 \% \mathrm{Cl})\end{array}$ & $P$-value \\
\hline Current smoking & $89(7.4)$ & $4(17.4)$ & $2.63(0.88-7.90)$ & 0.091 & & \\
\hline Alcohol consumption & $133(11.1)$ & $5(21.7)$ & $2.23(0.82-6.11)$ & 0.170 & & \\
\hline Hypertension & $84(7.9)$ & $21(8.8)$ & $1.13(0.69-1.87)$ & 0.692 & & \\
\hline Metabolic syndrome & $243(20.2)$ & $2(8.7)$ & $0.38(0.09-1.61)$ & 0.289 & & \\
\hline Exercise ( $\geq 3$ times/wk) & $271(22.6)$ & $5(21.7)$ & $0.95(0.35-2.59)$ & 1.000 & & \\
\hline \multicolumn{7}{|l|}{ Age (yr) } \\
\hline$\leq 59$ & $931(77.5)$ & $11(47.8)$ & 1 (reference) & & 1 (reference) & \\
\hline$\geq 60$ & $270(22.5)$ & $12(52.2)$ & $3.76(1.64-8.62)$ & 0.002 & $3.50(1.51-8.11)$ & 0.004 \\
\hline Male sex & $544(45.3)$ & $19(82.6)$ & $5.74(1.94-16.96)$ & $<0.001$ & $5.55(1.86-16.5)$ & 0.002 \\
\hline BMI $\left(\geq 25 \mathrm{~kg} / \mathrm{m}^{2}\right)$ & $440(36.6)$ & $8(34.8)$ & $0.92(0.39-2.19)$ & 0.855 & & \\
\hline Nonvegetarian diet & $18(3.0)$ & $5(21.7)$ & $3.77(1.39-10.21)$ & 0.006 & $3.90(1.43-10.67)$ & 0.008 \\
\hline
\end{tabular}

${ }^{a}$ Adjusted for age, male and vegetarian diet.

sis in Asians. Vegetarianism was found to be a protective factor for asymptomatic colonic diverticulosis even after adjusting for several confounding factors. Regardless of the location of diverticulosis, vegetarianism showed a protective effect. Old age, male sex, and high BMI were independently associated with the risk of asymptomatic colonic diverticulosis. The prevalence of diverticulosis in this study was $10.8 \%$ in the general population group which is similar with that of previous reports.

In our study, the risk factors for diverticulosis were similar between right-sided and left-sided diverticulosis. In Asians, colonic diverticulosis occurs mainly in the right-sided colon, whereas the sigmoid colon is more commonly involved in Westerners. Most Korean studies, including this study, have also reported that colonic diverticula are more common in the right side than in the left side (about $80 \%$ ). ${ }^{14,20}$ The pathogeneses of right-sided and left-sided diverticulosis may differ. However, a Japanese study reported that the etiology of right-sided diverticulosis in Asians may be similar to that of left-sided diverticulosis in Western countries. The authors concluded that the differences in location may stand for a difference in the morphology of colon between Asians and Western people, rather than differences in environment. ${ }^{21}$

In addition to race or genetic influences, many investigators have showed that dietary pattern, colonic abnormal motility, and alterations in colonic structure are the causes of diverticulosis development. ${ }^{3,14}$ Painter and Burkitt ${ }^{17}$ first suggested that a fiber deficiency is an etiology of diverticular disease. This hy- pothesis is that the deficiency of dietary fiber intake causes reduced intestinal contents to make bowel lumen smaller. Subsequently, pressure from muscular contractions is applied to the colonic wall more than to the luminal contents. High pressure on the intestinal wall causes the development of colonic diverticulosis at the weak points of wall. ${ }^{17}$ In 1985, a lifespan study using 1,800 Wistar rats showed a significant inverse association between the incidence of diverticulosis and the concentration of fiber in their diets. This study offers strong support for the hypothesis of Painter and Burkitt that human diverticular disease is caused by fiber deficiency, provided the association can be extrapolated from rats to humans. ${ }^{22}$

In contrast, some studies showed no relationship between fiber consumption and asymptomatic diverticulosis. A recent study ${ }^{2}$ of over 2,000 patients who underwent colonoscopy in the United States revealed that high intake of fiber did not reduce the prevalence of diverticulosis. Dietary information was gathered using questionnaire, a food frequency questionnaire with over 100 food items. This study found that dose-dependent higher fiber diets were actually associated with a higher prevalence of diverticulosis. In a Korean study of 848 subjects who underwent colonoscopy, ${ }^{14}$ no correlation between a highfiber diet and colonic diverticula was observed. Information about subjects' dietary styles was obtained through a questionnaire using the mini dietary assessment (MDA) index. This index scores the frequencies of vegetable, fruit, and kimchi intakes. The mean fiber MDA score of subjects with diverticulo- 
sis was not significantly different with that of those without. Reproducibility problems may result from the use of repeated 24-hour or quantitative dietary recalls; therefore, a study of confirmed vegetarians, such as Buddhist monks, might solve this problem.

In Buddhism, food is considered to be the only means of maintaining life; pleasure is excluded. ${ }^{23}$ Buddhist monks consume a vegetarian diet according to specific rules. ${ }^{24,25}$ In general, the Korean Buddhist diet avoid food of any animal origin except milk, several stinky vegetables including garlic and welsh onion, alcohol, and excessive quantity of processed food. ${ }^{25,26}$ Unlike the previous studies that investigated vegetarians using interviews or questionnaires, our study yielded statistically significant results of the prevalence of diverticulosis in Buddhist monks who are strict vegetarians compared with that in the general population.

In this study, the prevalence of diverticulosis was age-dependent, increasing with increasing age. This indicated a dose-dependent relationship between age and the risk of colonic diverticulosis which was compatible with many previous studies. ${ }^{22,27-29}$ The prevalence of diverticulosis ranges from less than $10 \%$ in subjects younger than 40 years to an about $70 \%$ in those older than 80 years in Western countries. ${ }^{5,30-32}$

Although an equal distribution or a female preponderance was suggested in a Western study, ${ }^{1}$ a male preponderance was reported in previous Asian studies. ${ }^{13,20,33-35}$ The ratio of men to women in our study was 2.02 which is similar to that of previous studies. A future study should investigate the cause of this male preponderance.

The prevalence of obesity has grown considerably through the years, and this has been associated with several GI diseases, including diverticular disease. In a recent systematic review, it was suggested that even moderate increases in BMI may increase not only the risk of diverticular disease, but also diverticular disease complications. ${ }^{36}$ Notably, the BMI of Buddhist monks was higher than that of the general population; this was consistent with other previous studies of Korean Buddhist vegetarians. ${ }^{26,37-41}$ The reason for this is that Buddhist monks' calorie- and carbohydrate intakes were significantly higher, and their preference for sweet or salty food was high. It may also be caused by a lack of exercise as less than $20 \%$ of Buddhist monks exercise 2 or more times a week. ${ }^{38,42}$ As shown in Table 1, although Buddhist monks had a higher prevalence of obesity and metabolic syndrome, which were risk factors for diverticulosis in several studies, than the general population, it could be speculated that a vegetarian diet had a strong protective effect against colonic diverticulosis.

This study had several strong points. Firstly, we enrolled Buddhist monks as a pure vegetarian group. They are obligatory vegetarians for the spiritual reason. This ensured an accurate assessment of the effect of vegetarian diet on diverticulosis. Secondly, the collected data had high quality because all the measurements were taken by skilled personnel with standardized protocol. Third, we analyzed the risk factors according to the location of the diverticula.

There were also several weak points in this study. Firstly, because it was a retrospective, cross-sectional study, the temporal association and causality between vegetarianism and asymptomatic diverticulosis could not be evaluated. Secondly, although a multivariate analysis was performed, no subject in the vegetarian group smoked or drank alcohol, and these were risk factors in several studies. ${ }^{43,44}$ This may have limited the ability to adjust for multiple variables. Thirdly, we did not evaluate medications, including NSAIDs, statins, or opiates, which were reported to be risk factors for diverticular disease ${ }^{45}$ due to missing data. However, no association between these medications and asymptomatic diverticulosis has been reported Forth, we did not evaluate the association between dietary fiber intake and symptomatic colonic diverticulosis. Among Buddhist monks who underwent colonoscopy, only 1 person replied that he had history of diverticulitis. This may result from the fact that questionnaire included open question about past medical history, not specific question about diverticular disease.

In conclusion, old age, male sex, higher BMI, and a nonvegetarian diet were independently associated with colonic diverticulosis. Therefore, our study suggested that a vegetarian diet is inversely associated with asymptomatic colonic diverticulosis irrespective of the location of the diverticulosis in Asians.

\section{FINANCIAL SUPPORT}

This work was supported by Dongguk University Research Fund 2016.

\section{CONFLICT OF INTEREST}

No potential conflict of interest relevant to this article was reported.

\section{AUTHOR CONTRIBUTION}

Conception and design: Kang HW. Data collection: Bong J, Cho 
H, Nam JH, Jang DK. Writing: Bong J, Kang HW, Jang DK. Review and manuscript supervision: Kim JH, Lee JK, Lim YJ, Koh MS, Lee JH. Approval of final manuscript: all authors.

\section{ORCID}

$\begin{array}{ll}\text { Bong J } & \text { https://orcid.org/0000-0002-3128-3790 } \\ \text { Kang HW } & \text { https://orcid.org/0000-0003-3431-0827 } \\ \text { Cho H } & \text { https://orcid.org/0000-0003-3694-8111 } \\ \text { Nam JH } & \text { https://orcid.org/0000-0002-7083-7581 } \\ \text { Jang DK } & \text { https://orcid.org/0000-0001-6642-6635 } \\ \text { Kim JH } & \text { https://orcid.org/0000-0001-6270-3703 } \\ \text { Lee JK } & \text { https://orcid.org/0000-0002-2694-3598 } \\ \text { Lim YJ } & \text { https://orcid.org/0000-0002-3279-332X } \\ \text { Koh MS } & \text { https://orcid.org/0000-0002-3534-8459 } \\ \text { Lee JH } & \text { https://orcid.org/0000-0002-8013-3262 }\end{array}$

\section{SUPPLEMENTARY MATERIAL}

Supplementary materials are available at the Intestinal Research website (https://www.irjournal.org).

\section{REFERENCES}

1. Parks TG. Natural history of diverticular disease of the colon. Clin Gastroenterol 1975;4:53-69.

2. Peery AF, Barrett PR, Park D, et al. A high-fiber diet does not protect against asymptomatic diverticulosis. Gastroenterology 2012;142:266-272.

3. Floch MH, Bina I. The natural history of diverticulitis: fact and theory. J Clin Gastroenterol 2004;38(5 Suppl 1):S2-S7.

4. Sandler RS, Everhart JE, Donowitz M, et al. The burden of selected digestive diseases in the United States. Gastroenterology 2002;122:1500-1511.

5. Everhart JE, Ruhl CE. Burden of digestive diseases in the United States part II: lower gastrointestinal diseases. Gastroenterology 2009;136:741-754.

6. Peery AF, Dellon ES, Lund J, et al. Burden of gastrointestinal disease in the United States: 2012 update. Gastroenterology 2012;143:1179-1187.

7. Kang JY, Hoare J, Tinto A, et al. Diverticular disease of the colon--on the rise: a study of hospital admissions in England between 1989/1990 and 1999/2000. Aliment Pharmacol Ther 2003;17:1189-1195.

8. Shaheen NJ, Hansen RA, Morgan DR, et al. The burden of gastrointestinal and liver diseases, 2006. Am J Gastroenterol 2006;
101:2128-2138.

9. Levy N, Stermer E, Simon J. The changing epidemiology of diverticular disease in Israel. Dis Colon Rectum 1985;28:416-418.

10. Fong SS, Tan EY, Foo A, Sim R, Cheong DM. The changing trend of diverticular disease in a developing nation. Colorectal Dis 2011;13:312-316.

11. Toda S, Ito Y, Mizuno M, et al. Asymptomatic diverticulosis identified by computed tomography is not a risk factor for enteric peritonitis. Nephrol Dial Transplant 2012;27:2511-2516.

12. Kiguli-Malwadde E, Kasozi H. Diverticular disease of the colon in Kampala, Uganda. Afr Health Sci 2002;2:29-32.

13. Song JH, Huh JG, Kim YS, et al. Clinical characteristics of colonic diverticular disease diagnosed with colonoscopy. Intest Res 2008;6:110-115.

14. Song JH, Kim YS, Lee JH, et al. Clinical characteristics of colonic diverticulosis in Korea: a prospective study. Korean J Intern Med 2010;25:140-146.

15. Liu PH, Cao Y, Keeley BR, et al. Adherence to a healthy lifestyle is associated with a lower risk of diverticulitis among men. Am J Gastroenterol 2017;112:1868-1876.

16. Aldoori WH, Giovannucci EL, Rimm EB, Wing AL, Trichopoulos DV, Willett WC. A prospective study of diet and the risk of symptomatic diverticular disease in men. Am J Clin Nutr 1994; 60:757-764.

17. Painter NS, Burkitt DP. Diverticular disease of the colon: a deficiency disease of Western civilization. Br Med J 1971;2:450454.

18. Fisher N, Berry CS, Fearn T, Gregory JA, Hardy J. Cereal dietary fiber consumption and diverticular disease: a lifespan study in rats. Am J Clin Nutr 1985;42:788-804.

19. Grundy SM, Cleeman JI, Daniels SR, et al. Diagnosis and management of the metabolic syndrome: an American Heart Association/National Heart, Lung, and Blood Institute Scientific Statement. Circulation 2005;112:2735-2752.

20. Kwoen YT, Han SI, Chung SK, Bahk YW. Changing incidence of diverticular disease of the colon in Korea: a serial radiologic study (report III). J Korean Radiol Soc 1988;24:840-843.

21. Nakaji S, Danjo K, Munakata A, et al. Comparison of etiology of right-sided diverticula in Japan with that of left-sided diverticula in the West. Int J Colorectal Dis 2002;17:365-373.

22. Strate LL, Modi R, Cohen E, Spiegel BM. Diverticular disease as a chronic illness: evolving epidemiologic and clinical insights. Am J Gastroenterol 2012;107:1486-1493.

23. Seo HK. Dietary life in Buddhist temple. J Korean Soc Food Cult 1995;10:497-503.

24. Han SJ, Lee SY. A study on dietary behavior and food prefer- 
ence of Sramanera-Sramanerika monks in nationwide Buddhist monk's universities. Korean J Community Nutr 2017;22: $387-400$.

25. Seo HK. Food culture of Buddhism. Asian Comp Folk 2003;24: 197-226

26. Lee Y, Krawinkel M. Body composition and nutrient intake of Buddhist vegetarians. Asia Pac J Clin Nutr 2009;18:265-271.

27. Kim SY, Kim YS, Kim HT, et al. A prospective study of factors influencing on the clinical characteristics of colonic diverticulosis. Korean J Gastroenterol 2013;62:97-103.

28. Comparato G, Pilotto A, Franzè A, Franceschi M, Di Mario F. Diverticular disease in the elderly. Dig Dis 2007;25:151-159.

29. Yamamichi N, Shimamoto T, Takahashi Y, et al. Trend and risk factors of diverticulosis in Japan: age, gender, and lifestyle/metabolic-related factors may cooperatively affect on the colorectal diverticula formation. PLoS One 2015;10:e0123688.

30. Jacobs DO. Clinical practice: diverticulitis. N Engl J Med 2007; 357:2057-2066.

31. Welch CE, Allen AW, Donaldson GA. An appraisal of resection of the colon for diverticulitis of the sigmoid. Ann Surg 1953; 138:332-343.

32. Painter NS, Truelove SC, Ardran GM, Tuckey M. Segmentation and the localization of intraluminal pressures in the human colon, with special reference to the pathogenesis of colonic diverticula. Gastroenterology 1965;49:169-177.

33. Choi CS, Choi SC, Seo GS, et al. Association between diverticulosis and colonic neoplasm in Koreans. Korean J Gastroenterol 2007;49:364-368.

34. Kim JS, Cha SG, Kim YT, et al. The prevalence and clinical features of diverticular disease of the colon. Korean J Gastroenterol 1993;25:305-314.

35. Yang F, Zheng Y, Jiang X, et al. Sex differences in risk factors of uncomplicated colonic diverticulosis in a metropolitan area from Northern China. Sci Rep 2018;8:138.

36. Aune D, Sen A, Leitzmann MF, Norat T, Tonstad S, Vatten LJ. Body mass index and physical activity and the risk of diverticular disease: a systematic review and meta-analysis of prospective studies. Eur J Nutr 2017;56:2423-2438.

37. Sun Z, Welty FK, Dolnikowski GG, Lichtenstein AH, Schaefer EJ. Effects of a National Cholesterol Education Program Step II Diet on apolipoprotein A-IV metabolism within triacylglycerol-rich lipoproteins and plasma. Am J Clin Nutr 2001;74:308314.

38. Yoon JS, Lee WJ. A nutritional survey of Buddhist nuns. J Nutr Health 1982;15:268-276.

39. Jung JG, Kang HW, Hahn SJ, et al. Vegetarianism as a protective factor for reflux esophagitis: a retrospective, cross-sectional study between Buddhist priests and general population. Dig Dis Sci 2013;58:2244-2252.

40. Lee CG, Hahn SJ, Song MK, et al. Vegetarianism as a protective factor for colorectal adenoma and advanced adenoma in Asians. Dig Dis Sci 2014;59:1025-1035.

41. Jo HB, Lee JK, Choi MY, et al. Is the prevalence of gallbladder polyp different between vegetarians and general population? Korean J Gastroenterol 2015;66:268-273.

42. Park HY, Lee SY, Lee YH. A study of dietary life and state of health of Buddhist nuns in the Seoul area. J East Asian Soc Dietary Life 2002;12:343-351.

43. Wang FW, Chuang HY, Tu MS, et al. Prevalence and risk factors of asymptomatic colorectal diverticulosis in Taiwan. BMC Gastroenterol 2015;15:40.

44. Hjern F, Wolk A, Håkansson N. Smoking and the risk of diverticular disease in women. Br J Surg 2011;98:997-1002.

45. Kinjo K, Matsui T, Hisabe T, et al. Risk factors for severity of colonic diverticular hemorrhage. Intest Res 2018;16:458-466. 
See "Vegetarianism as a protective factor for asymptomatic colonic diverticulosis in Asians: a retrospective cross-sectional and case-control study" on page 121-129.

Supplementary Material 1. Questionnaire

\section{Past Medical History}

Please give details of any important illness, operation or medications:

\begin{tabular}{|l|l|}
\hline Current or Past Medical Problems & Dates of Diagnosis \\
\hline & \\
\hline & \\
\hline & \\
\hline & \\
\hline
\end{tabular}

\begin{tabular}{|l|l|l|}
\hline Surgeries & Dates & Reason \\
\hline & & \\
\hline & & \\
\hline & & \\
\hline & & \\
\hline
\end{tabular}

\begin{tabular}{|l|l|l|}
\hline Medications & Dosage/Frequency & Reason \\
\hline & & \\
\hline & & \\
\hline & & \\
\hline & & \\
\hline
\end{tabular}

\section{Life Style}

- Check one of the following about smoking within recent 1 year
$\square$ Never smoked
$\square$ Former smoked
$\square$ Smoke some days
$\square$ Smoke every day

If you smoke or used to smoke, how many packs do/did you smoke per day?

How many years did you smoke/have you smoked?

If you quit, when did you quit?

- How often do you drink alcohol on average?
$\square$ Never
$\square<4 /$ month
$\square$ 1-3/week
$\square$ 4-6/week
$\square$ daily

If you drink alcohol, please indicate the quantity per week of each

- Soju glass (40cc) of Soju 
- Beer glasses (250cc) of beer

- Wine glass (85cc) of wine

- Shot (25cc) of hard liquor (such as whisky)

- Do you take regular exercise? $\square$ no $\square$ yes

If yes, what kind of exercise do you take?

How often have you ate meat

$\square<$ 1/week, $\square$ 1-2/week, $\square$ 3-6/week, $\square$ daily

How long do you exercise on average when you take exercise? minutes

\section{Symptoms}

$\begin{array}{lll}\text { - Abdominal pain } & \square \text { none } & \square \text { mild } \square \text { moderate } \square \text { severe } \\ \text { - Dyspepsia } & \square \text { none } \quad \square \text { mild } \square \text { moderate } \square \text { severe } \\ \text { - Nausea/vomiting } & \square \text { none } \quad \square \text { yes } \\ \text { - Diarrhea } & \square \text { none } \quad \square \text { yes (defecation /day) } \\ \text { - Constipation } & \square \text { none } \square \text { yes (defecation /week) } \\ \text { - Jaundice } & \square \text { none } \square \text { yes } \\ \text { - Black stool } & \square \text { none } \square \text { yes } \\ \text { - Blood in stool } & \square \text { none } \square \text { yes } \\ \text { - Difficulty in swallowing } & \square \text { none } \quad \square \text { yes }\end{array}$

\section{Diet}

- How often have you eat red meat or poultry?

$\square$ Never (vegetarian), $\square \leq$ 1/week, $\square$ 2-3/week, $\square \geq$ 4/week 